\title{
April Updates: People and Places
}

\begin{abstract}
Reproducible addiction research Molly Bogue, an addiction researcher at the Jackson Laboratory who works on the Mouse Phenome Project, has recently received a grant worth over $\$ 750,000$ from the National Institute on Drug Abuse to improve the reproducibility of preclinical addiction research. Bogue will collaborate with Yoav Benjamini, an applied statistics professor at the Tel Aviv University in Israel, to develop statistical tools to reduce the impact of "noise", the interaction between genetics and the lab environment, when determining the significance of a genotype effect in mouse-based studies.

Bogue commented in a press release, "Our approach is to use the interaction noise to generate an adjusted 'yardstick' against which genotype differences are judged, raising the benchmark for declaring a genotype effect significant and trading some statistical power for ensuring replicability."
\end{abstract}

\section{Rs updates in the UK}

The UK-based National Centre for the Replacement, Refinement, \& Reduction of Animals in Research (NC3Rs) has welcome new board members and funded a new round of fellowships in recent weeks. Four fellows have received funding for their projects on replacing and reducing the use of research animals. Olga Baron of King's College London and Anne Herrmann of the University of Liverpool were awarded David Sainsbury Fellowships, intended for intermediate stage researchers transitioning to independent careers. Baron's work will focus on developing a Drosophila model for muscular pain, while Herrmann will look to chick embryos as a replacement for rodent models of tumor metastasis. Two Training Fellowships were also awarded to junior researchers Carola Morell of the University of Cambridge, who will study the use of human pluripotent stem cells to model non-alcoholic fatty liver disease, and to Scott Davies of the University of Birmingham; his fellowship will focus on the validation of multiphoton imaging of liver tissues as a tool for drug discovery.

New board members include: Paul Garside from Wellcome Centre for Molecular Parasitology and the Immunobiology Department of the University of Glasgow; David Lovell from St. George's Medical School, University of London; and Jon Timmis from the Department of Electronic Engineering at the University of York. This non-executive board, chaired by Stephen Holgate from the University of Southampton, advises on the NC3Rs' strategy, mission delivery, and financial planning.

\section{NIH genome editing}

The National Institutes of Health has announced the launch of a new program, Somatic Cell Genome Editing, with plans to award approximately $\$ 190$ million

\section{Careers Update}

Anna Lowit has been awarded the Society of Toxicology's 2018 Enhancement of Animal Welfare Award. The award has been given annually since 2000 in recognition of a Society member's efforts towards replacing, refining, or reducing the need for animals in toxicological research through either a seminal piece of work or long-term contributions to toxicological science and animal welfare.

Lowit, a senior advisor to the US Environmental Protection Agency (EPA)'s Office of Pesticide Programs since 2016, has led initiatives at the agency to advance adoption of new in vitro and in silico approaches for testing acute, oral, dermal, and inhalation toxicity as well as eye and skin sensitization. She also represents the EPA on the Interagency Coordinating Committee on the Validation of Alternative Methods.

She received her $\mathrm{PhD}$ in environmental toxicology from the University of Tennessee and has worked for the EPA since 1998. The Enhancement of Animal Welfare Award was presented at the Society of Toxicology's 2018 Meeting in March.

over the next six years to researchers studying genome editing as a treatment for genetic diseases. Two of the six funding opportunities will support the development of reporter models for testing in vivo editing technologies, in rodents (RFA-RM-18-012) and in large animals (RFA-RM-18-013).

\section{Phase II support}

The Jackson Laboratory has received a \$12.5 million grant from the Maine Technology Institute (MTI) to fund the second phase of construction of a new, 134,900-square-foot research mouse production facility, scheduled to open this summer in Ellsworth, ME. Phase II of the three-phase project will outfit the second section of the facility with material processing, material conveyance, and animal racking and caging equipment. MTI also funded the pilot phase in of the project in 2015 to confirm feasibility of the facility; groundbreaking on the project occurred in August 2016.

"We're grateful for MTI's belief in the importance of our work," Chief Operating Officer \& EVP Charles Hewett commented in a press release. "The automated systems we're implementing will significantly increase production safety and efficiency, and enhance product quality. Our new Ellsworth facility is an important step in advancing The Jackson Laboratory's position as a global leader in research mouse production."

\section{Translation in Kansas}

The Kansas State University College of Veterinary Medicine is expanding its work in translational and comparative oncology. Established late last year with funding from the Johnson Cancer Research Center, the Center of Excellence for Translational and Comparative Oncology Research (CETCOR) will assist Kansas State researchers with discovery and development of preclinical and clinical treatments for a wide variety of cancers found in both humans and animals. CETCOR is directed by Dr. Raelene Wouda, and its inaugural symposium was held on March $17^{\text {th }}$.

Published online: 26 March 2018 https://doi.org/10.1038/s41684-018-0023-X 